\title{
HEADEDNESS IN DIMINUTIVE FORMATION: EVIDENCE FROM MODERN GREEK AND ITS DIALECTAL VARIATION*
}

\author{
DIMITRA MELISSAROPOULOU - ANGELA RALLI \\ Department of Philology \\ University of Patras \\ 26504, Rio Patras \\ Greece \\ dmelissa@upatras.gr; ralli@upatras.gr
}

\begin{abstract}
The paper deals with the notion of headedness, as applied to dimutive suffixation. Following evidence from Modern Greek and its dialects, we propose that diminutive suffixes are heads of their constructions on the basis of certain criteria. First, the inflectional paradigms of a number of diminutive formations show irregularities and gaps that are not justified by the inflectional behavior of the base. Second, diminutive suffixes may change a semantic feature of the base, specialize its meaning, and transmit to the formation the morphosyntactic features of gender and inflection class. Moreover, they are subject to subcategorization and selectional criteria, as opposed to inflectional markers, the distribution of which is more or less free. Assuming that headedness characterizes derivational suffixes, but not the inflectional ones, we demonstrate that Modern Greek diminution belongs to the derivational domain.
\end{abstract}

Keywords: headedness, diminution, suffixation, dialectal variation, Modern Greek

\section{Introduction}

The notion of head has been applied to morphology by a number of linguists (see, among others, Williams 1981; Selkirk 1982; Di Sciullo-

* We thank the European Social Fund (ESF), Operational Program for Educational and Vocational Training II (EPEAEK II), and particularly the Program HERAKLITOS, for funding the above work. We are indebted to Franco Fanciullo, Giorgio Filieri, and Mark Janse for their assistance with data from Grico and Cappadocian. 
Williams 1987; Scalise 1988, and Lieber 1989) as a theoretical tool to account for the properties of morphologically complex words. More particularly, in a morpheme-based approach derivational suffixes are usually seen as heads of their formations, since most of them are responsible for determining the grammatical category of derived words (Scalise 1994, 184). However, there is no general agreement with respect to the headedness and derivational nature of evaluative suffixes, particularly of diminutive suffixes. On the one hand, on the basis of data drawn from languages such as Fula and Kikuyu, Anderson (1992) claims that evaluative material is like inflection, the latter being exempted from the headedness status. His basic arguments are the full productivity of diminutive suffixes, their integration into the nominal inflectional paradigm, as well as their interaction and alternation with the plural marker, which is generally considered to be inflectional. On the other hand, Ralli (1988) and Booij (1995) argue in favor of diminutive suffixes being derivational and heads, by using data from Greek and Dutch, respectively. According to their analysis, diminutive suffixes may not change the category of the base, but they determine the lexical subclass of their formations as well as their gender and inflection class. Within the same spirit, Bauer (1997) shows that in Klamath (described by Barker 1964) diminution behaves like a derivational process too. An intermediate position is taken by Dressler and Merlini-Barbaresi $(1992 ; 1994)$ and Scalise (1988). Dressler and Merlini-Barbaresi $(1992 ; 1994)$ suggest that diminutive affixes are not prototypical representatives of derivation, and thus, cannot be heads. Crucially, Scalise (1988) proposes that Italian diminutive affixes belong to a subcomponent situated between derivation and inflection, since they display the following characteristics: ${ }^{1}$

(a) Like inflectional markers, diminutive suffixes do not change the category of the base (see also Grandi 2002).

(b) They are peripheral in word formation, but appear before inflection.

(c) They violate the Unitary Base Hypothesis (Aronoff 1976), that is they do not select bases of a unique category.

${ }^{1}$ Stump (1993) has discussed the theoretical and the empirical problems of this proposal on a cross-linguistic level, showing that we cannot prove on a theoretical level that these properties are typical of evaluative suffixes, because they may systematically characterize other derivational suffixes of the same language. Bauer $(1997,551)$ also claims that "while it may be possible to define evaluative morphology in terms of such a set of criteria, it does not seem that these criteria universally match what might be thought of as evaluative morphology in a more pre-theoretical sense".

Acta Linguistica Hungarica 55, 2008 
In this paper, we argue that diminutive suffixes have a number of properties which make them derivational and heads of their constructions. We show that they impose selectional restrictions on the base, may change its semantic features, modify its grammatical gender and inflection class, and their combination with the base may cause unpredictable gaps, which are not proper to the base. Furthermore, we argue that the 'strength' of the derivational status and the headship properties of diminutive suffixes are subject to variation from one language to another, and to some extent, from one dialect to another within the same linguistic system.

In an effort to generalize and account for the peculiar behavior of diminutive suffixes, we adopt the idea of a morphological continuum (Bybee 1985), where derivational and inflectional affixes are at the two poles (see also Ralli 2005). ${ }^{2}$ We propose that diminutive affixes are situated in between, and appear closer to one pole or to the other, depending on the properties of the particular linguistic system, and the properties of the particular suffix. This position is within the spirit of Scalise's (1988) proposal about evaluative affixation being situated in a morphological subcomponent between derivation and inflection, but also differs from it in that it denies a radical separation between the three subcomponents, i.e., derivation, evaluative morphology and inflection.

We illustrate our claims with evidence from Standard Modern Greek (SMG), and the Modern Greek dialects from Kydonies (Aivaliot), Cappadocia, Pontus (Pontic), and South Italy (Grico). ${ }^{3}$ Crucially, dialectal evidence supports our claims about the general derivational nature and the headedness properties of diminutive suffixes. It is shown that even the most peripheral dialects of Modern Greek do not only keep, but also reinforce, these properties, sometimes against the type of diminution that characterizes a neighboring language, which has strongly influenced them.

The paper is structured in four parts: after the introduction, section 2 contains the basic criteria defining the derivational character of Greek diminutive suffixes: limited categorial sensitivity, selectional restrictions,

${ }^{2}$ For a detailed account of the differences between inflection and derivation, see Dressler (1989).

${ }^{3}$ Pontic, Cappadocian and Aivaliot were once spoken in the Ottoman Empire (areas of Northwest Turkey, Cappadocia, and West Turkey, respectively). After the end of the war between Greece and Turkey in 1922, the dialects continue to be spoken in Greece, within communities of first, second and third generation refugees. The dialectal data is taken from available written material, as well as from the oral corpora of the Modern Greek Dialects Laboratory (MGDL) of the University of Patras. 
alternation between diminutive suffixes, and the non-exclusive peripheral position. In section $\mathbf{3}$ the headedness issue is examined. We show that diminutive suffixes are heads of their constructions, since they are responsible for the basic morphosyntactic features characterizing these constructions. Finally, in section $\mathbf{4}$ we propose that in a morphological continuum containing all kinds of affixes, the diminutive suffixes are situated between the two poles of derivation and inflection, and the fact that they may be closer to the one or to the other pole depends on the particular language. In this respect, the contribution of dialectal evidence is particularly significant.

\section{Diminutive suffixes and derivation}

In order to define the possible headship properties of diminutive suffixes, we should determine first whether they belong to derivation. In fact, with the help of a number of criteria we conclude that it is reasonable to characterize them as derivational. These criteria refer to the categorial and selectional restrictions, the possibility to have alternating diminutive suffixes for the same base, and the order of word-internal constituents.

\subsection{Categorial and selectional restrictions}

As mentioned above, there are languages where diminutive suffixes do not change the category of the base. Italian is such a language, where, as shown by Scalise $(1988 ; 1994)$ and Grandi $(2002)$, diminutive suffixes are assumed to be category neutral. However, categorial neutrality of diminutive suffixation may not apply to all languages. For instance, according to Booij $(2005,53)$ the Dutch suffix - $(t) j e$ determines the nominal category of diminutive nouns of verbal and adjectival bases:

(1) blond $_{\mathrm{A}}>$ blondje $_{\mathrm{N}}$

blond blond girl

speel $_{\mathrm{V}}>$ speeltje $_{\mathrm{N}}$

play toy

Moreover, categorial neutrality is not an exclusive property of diminutive suffixes, which makes them behave like inflection, but may characterize a number of derivational suffixes too. In the examples under (2), the Greek nominal suffixes -aris and -dzis, denoting a property or a profession, as 
well as the suffix -ia that forms abstract nouns, select nouns in order to build nouns as well:

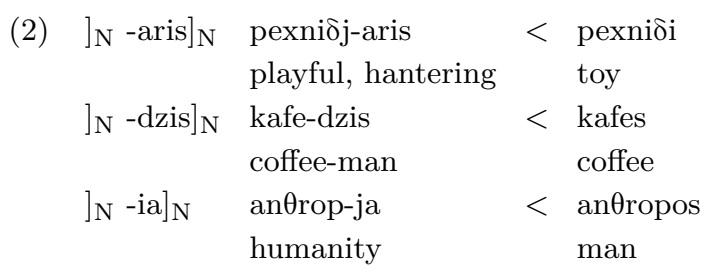

In addition, the presence of Greek diminutive suffixes demands selectional restrictions of syntactic, morphological and semantic nature, as opposed to inflectional markers, the distribution of which is more or less free. In the following examples taken from SMG and the Pontic dialect we see that the suffixes -aki, -u/itsikos and -opon have specific subcategorisation requirements, and their noun formations have an explicit meaning of 'little $\mathrm{X}$ ' ${ }^{4}$

(3) (a) SMG

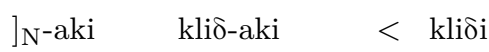

$$
\begin{aligned}
& \text { little key key } \\
& \text { *] } \text { A-aki } *_{\text {xodr-aki }}<\text { xodros } \\
& \text { fatty fat } \\
& \text { ]A-utsikos xodr-utsikos }<\text { xodros } \\
& \text { fatty fat }
\end{aligned}
$$

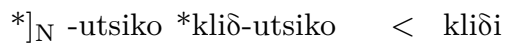

(b) Pontic (Koutita-Kaimaki 1984)

$$
\begin{aligned}
& ]_{\mathrm{N}} \text {-opon elaf-opon }<\text { elafi } \\
& \text { little deer deer } \\
& \left.{ }^{*}\right]_{\mathrm{A}} \text {-opon }{ }^{*} \text { psil-opon }<\text { psilos } \\
& \text { little tall tall } \\
& ]_{\mathrm{A} \text {-itsikos }} \text { psil-itsikos }<\text { psilos } \\
& \text { little tall tall } \\
& \left.{ }^{*}\right]_{\mathrm{N}} \text {-itsiko } * \text { elaf-itsiko }<\text { elafi } \\
& \text { little deer deer }
\end{aligned}
$$

\footnotetext{
${ }^{4}$ For diminutive formations that are based on adjectives there may be an expressive reading beside the one with the meaning of 'little X', the latter being always present.
} 
Gender requirements are also imposed by several diminutive suffixes. For instance, the SMG suffix -ula and its correspondent dialectal - $u \delta a$ (Aivaliot) and -eddha (Grico) are attached only to feminine bases:

(4) (a) SMG

$$
\begin{aligned}
& \text {-ula port-ula }<\text { porta }(\mathrm{Fem}) \\
& \text { little door door } \\
& \text { but } *_{\text {vaz-ula }}<\text { vazo (Neut) } \\
& \text { little vase vase }
\end{aligned}
$$

(b) Aivaliot (Ralli forthcoming, MGDL archive)

$$
\begin{aligned}
& \text {-uס́a avl-uóa < avli (Fem) } \\
& \text { little yard yard } \\
& \text { but *trapez-uóa < trapez (Neut) } \\
& \text { little table table }
\end{aligned}
$$

(c) Grico (Filieri 2001, MGDL archive)

$$
\begin{aligned}
& \text {-eddha ornit-eddha }<\text { ornita (Fem) } \\
& \text { little hen hen } \\
& \text { but } *_{\text {ner-eddha }}<\text { nero (Neut) } \\
& \text { little water water }
\end{aligned}
$$

Very often, the attachment of a diminutive suffix to a possible base is governed by the inflection class of the base. In (5) we list examples from Grico, where -aki selects only neuter nominal bases ending in $-i$, while $-u d d h i$ selects nominal and adjectival bases ending in -o.

(5) Grico (Filieri 2001, MGDL archive)
(a) -a(k)i kutal-ai $<$ kutali
little spoon spoon
$*_{\text {ner-aki }<\text { nero }}$
little water water
(b) -uddhi aderf-uddhi $<$ aderfo
ftex-uddhi $<$ ftexo
little poor poor
*kutal-uddhi $<$ kutali
little spoon spoon little brother brother

Finally, the presence of diminutive suffixes entails semantic restrictions. The Pontic -itsos or -itsis attach only to [+ animate] bases. Similarly, the Aivaliot $-i$ requires [- human] bases:

Acta Linguistica Hungarica 55, 2008 
(6) (a) Pontic (Oikonomidis 1958)

$$
\begin{aligned}
& \text {-itso/is peo-itsos < peoi } \mathrm{i} \\
& \text { little child child } \\
& \text { fil-itsis }<\text { filos } \\
& \text { little friend friend }
\end{aligned}
$$

(b) Aivaliot (idem.)

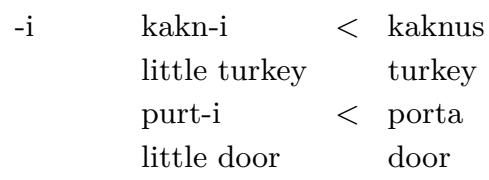

Therefore, bases are not freely selected by Greek diminutive suffixes. These selectional restrictions advocate a derivational status, and argue against attempts to list diminutive suffixes within inflectional material.

\subsection{Alternation}

Bauer (1983) has argued that derivation is characterized by low alternation in morphology, since it violates the Blocking Principle (Aronoff 1976; Scalise 1994), according to which if a suffix appears productively in a category X, it blocks the appearance of another suffix within the same category. However, as Katramadou (2001) has shown, high alternation is attested in the occurrence of SMG diminutive suffixes, and may be used as an argument against their derivational character:

(7) (a) SMG -ula, -itsa $a^{5}$ and -aki attaching to nouns

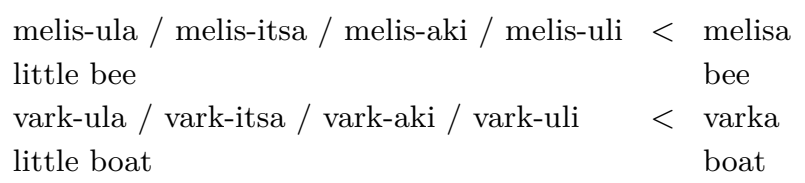

\footnotetext{
${ }^{5}$ According to Daltas $(1985,80)$, -ula and -itsa do not alternate when the former selects a base whose stem ends in /1/, (e.g., *kutal-ula but kutal-itsa 'little spoon') and the latter a stem ending in an affricate (e.g., *tarats-itsa but tarats-ula 'little terasse') or in /i/ (e.g., *istori-itsa but istori-ula 'little story'). In all the other cases they alternate, but -ula is more frequent that -itsa. In our view, these observations reflect only tendencies, since there is a considerable number of counterexamples.
} 
(b) SMG -uli and -utsik(o) attaching to adjectives

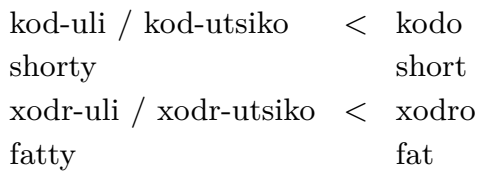

Alternation is not the general rule of the Greek language though, since Greek dialects do not accept alternation, or display a low degree of alternation of diminutive suffixes. For instance, in Grico, the distribution of diminutive suffixes is restricted by both gender and inflection class. ${ }^{6}$ As already shown, $-a(k) i$ selects only neuter nominal bases ending in - $i$ (8a), -eddha selects feminine bases, both nominal and adjectival (8b), and $-u d d h i$ combines with adjectival and nominal bases ending in -o (8c):

(8) Grico (Rohlfs 1977)

\begin{tabular}{|c|c|c|c|}
\hline (a) & $\mathrm{a}(\mathrm{k}) \mathrm{i}:$ & $\begin{array}{ll}\text { kutal-ai } & < \\
\text { little spoon } & < \\
\text { ped-ai } & <\text { little child }\end{array}$ & $\begin{array}{l}<\text { kutali } \\
\text { spoon } \\
<\begin{array}{l}\text { pedi } \\
\text { child }\end{array}\end{array}$ \\
\hline (b) & -eddha & $\begin{array}{l}\text { cater-eddha } \\
\text { little daughter } \\
\text { ftex-eddha } \\
\text { little poor }\end{array}$ & $\begin{aligned}< & \text { catera } \\
& \text { daughter } \\
< & \text { ftexi } \\
& \text { poor }\end{aligned}$ \\
\hline & -uddhi & $\begin{array}{l}\text { aderf-uddhi } \\
\text { little brother } \\
\text { ftex-uddhi } \\
\text { little poor }\end{array}$ & $\begin{aligned} &< \text { aderfo } \\
& \text { brother } \\
&< \text { ftexo } \\
& \text { poor }\end{aligned}$ \\
\hline
\end{tabular}

Notice that the other dialects under examination, i.e., Pontic, Cappadocian and Aivaliot, show a limited alternation between only two suffixes, the most productive neuter suffix, which attaches to nominal bases of all three genders (-opon in Pontic, -okko in Cappadocian and -el' in Aivaliot),${ }^{7}$ and the feminine suffix that combines with feminine bases (-itsa in Pontic and Cappadocian and $-u \delta a$ in Aivaliot). Examples of each dialect are shown in (9):

\footnotetext{
${ }^{6}$ There are few counterexamples: xronai and xronuddhi 'little year' pjatuddhi and piatai 'little plate'.

${ }^{7}$ Palatalization of $l$ is indicated as $l$ '.
} 
(9) (a) Pontic (Koutita-Kaimaki 1984)

\begin{tabular}{|c|c|c|}
\hline -opon & -itsa & \\
\hline nif-opon & nif-itsa & $<$ nife \\
\hline little bride & & bride \\
\hline aelaó-opon & aelaó-itsa & $<\operatorname{aela\delta i}(\mathrm{n})$ \\
\hline ittle cow & & cow \\
\hline
\end{tabular}

(b) Cappadocian (Janse forthcoming)

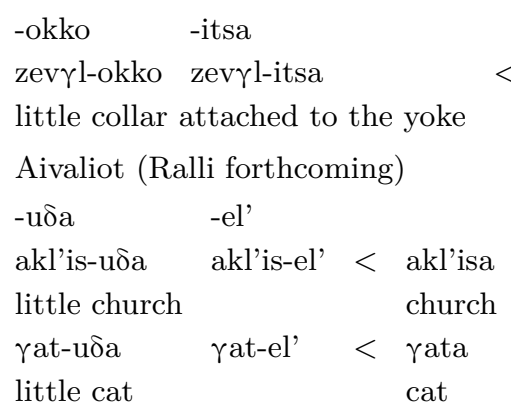

The presence of alternation in SMG or the low alternation rate in Modern Greek dialects find an explanation in Grandi's (Grandi 2002, 153) observations, who notes that alternation among diminutive suffixes is not completely free, but is due to two factors: (a) the referential meaning of diminutive suffixes (see also Bybee 1985), and (b) the kind of restrictions that diminutive suffixes obey; they attach to bases that pluralize, something which limits their applicability, although it does not determine their distribution. ${ }^{8}$ Grandi $(2002,154)$ adds that the tendency for alternation among diminutive suffixes is observed only in the standard forms and not in the dialectal ones, while the selection of one particular suffix can be an indication of social or geographical variation, that is, it may depend on extra-linguistic factors.

As a partial conclusion, we can state that although alternation is a general cross-linguistic characteristic of diminutive suffixes, evidence from dialects where alternation is either absent (Grico) or very limited (Cappadocian, Aivaliot and Pontic) supports their derivational status. In other words, the absence, or the low degree, of alternation of diminutive suffixes in Modern Greek dialects provides substantial evidence in favor of the thesis advocating their derivational nature.

8 Abstract nouns like sofia 'wisdom', which do not pluralize, do no diminutivize as well: *sofi-ula 'little wisdom' 


\subsection{Affixal order}

Scalise $(1988,235)$ has argued that within the word, diminutive suffixes are peripheral with respect to derivational suffixes, but internal with regard to inflectional ones, and that their position mirrors their position in grammar. On the contrary, Stump (1993); Bauer (1997) and Grandi (2002) have observed that this particular property is not proper to diminutive suffixes only, but may characterize other derivational suffixes too. For instance, in SMG peripheral (or closing) derivational suffixes are the productive adjectival $-i k-$, which denotes a property, and the participial adjectival -men-, which is followed only by inflection (e.g., -os):

(10) SMG
(a) organo-t-ik-os $<$ organo-ti-s organisational organisator
(b) xor-iz-men-os $<$ xor-iz-o divorced divorce

Crucially, the adjectival suffix $-i k$ - can be combined with adjectival bases containing a diminutive suffix. In these cases, the presence of $-i k$ - reinforces the diminutive meaning, as the following example illustrates:

(11) SMG

$$
\begin{aligned}
& \text { mikr-ul-ik-os }<\text { mikr-uli-s }<\text { mikr-os } \\
& \text { very very little very little little }
\end{aligned}
$$

Note that in this particular example the diminutive suffix -ul(i)- appears before the derivational suffix $-i k-$. Since $-u l(i)$ is very productive, we could assume that there are no strict ordering requirements regarding the position of diminutive suffixes within the word. In fact, some diminutive suffixes may be followed by certain derivational ones, provided that the latter are very productive, such as the $-i k$ - case. Since diminutive suffixes are not exclusively peripheral to morphologically complex words, we may accept them to be derivational.

\section{Headedness}

In the previous section, we argued that diminutive suffixes may be assigned a derivational status. Assuming this status, we can proceed into 
examining the ability of diminutive suffixes to function as heads. To this purpose, we check a number of features that could be used as criteria for the determination of headship properties.

\subsection{Semantic features}

As already mentioned (2.1), Scalise (1988) argues that diminutive suffixes are category preserving. Thus, they cannot be heads in structural terms. However, as both Scalise and Stump (1993) point out, this characteristic may be shown by pure derivative formations too, where a head does not change the category of the base, but may change its semantic information. For example, the English suffix -hood in nouns like manhood modifies the semantic information of the base, in that it changes the features [- abstract $]$ and [+ countable] into [+ abstract $]$ and [- countable], respectively.

The property of bringing a semantic change to the base is observed in many instances of Greek diminution. As an illustration, consider the diminutive suffixes -aki (SMG) and -el' (Aivaliot), which modify the feature $[ \pm$ countable], and cause a semantic specialization of the base, by narrowing its meaning:

(12) Semantic specialization

(a) SMG

$$
\begin{aligned}
& \text { psomi }[- \text { countable }]>\text { psom-aki } \quad[+ \text { countable }] \\
& \text { bread little bread } \\
& \text { uzo }[- \text { countable }]>\text { uz-aki } \quad[+ \text { countable }] \\
& \text { ouzo a glass of ouzo }
\end{aligned}
$$

(b) Aivaliot (Ralli forthcoming)

psumi $[-$ countable $]>$ psum-el' $[+$ countable $]$

uzo $[-$ countable $]>$ uz-el' $\quad[+$ countable $]$

Evidence in (12) shows that while the base is a common [-countable] noun, diminutive derivatives are [+ countable] and undergo a semantic specialization. For instance, uzel' in Aivaliot or uzaki in SMG are equivalent to a small glass of $u z o$. The sentence 'H $\pi\left\llcorner\mu \varepsilon \varepsilon\right.$ $\delta$ o ou $\alpha^{\alpha} \alpha\llcorner\alpha$ [ipjame dio

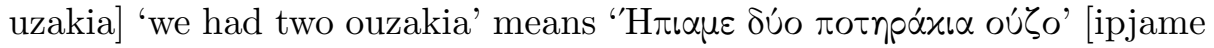
dio potirakia uzo] 'we had two glasses of ouzo'.

More rarely, a semantic change may lead to a non-compositional meaning (semantic lexicalization): 
(13) Non-compositional meaning

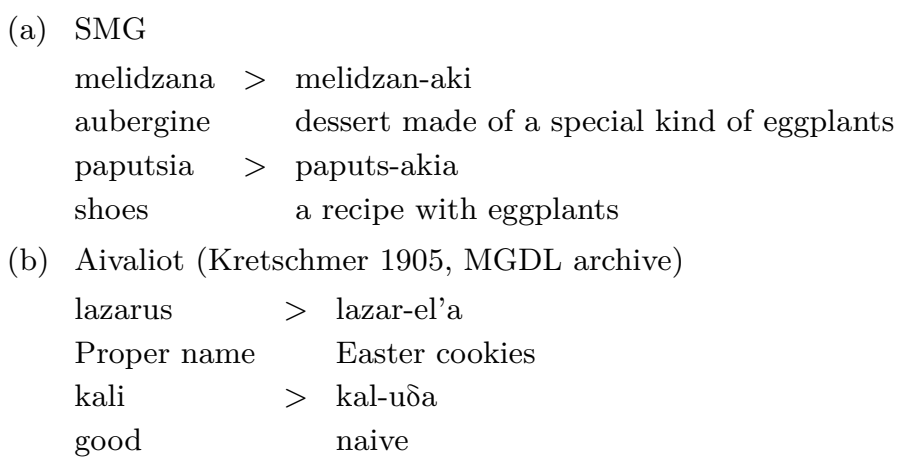

The examples in (13) show that the meaning of the diminutive form is entirely different from that of the base. For example, paputsakia are not small shoes but a recipe with eggplants. Note that this is a typical case of semantic lexicalization, which, according to Bauer (1997), characterizes derivation but not inflection. The particular phenomenon is common cross-linguistically, and offers further support to the claim about the headedness and the derivational status of diminutive suffixes.

\subsection{Gender}

There are languages, for instance Italian (Scalise 1988), where diminutive suffixes do not usually change the gender value of the base (e.g., uccell-ino 'little bird' < uccell-o 'bird'; strad-ina 'little road' < strad-a 'road'). However, this characteristic is not universal, since there are also languages with the opposite phenomenon. For instance, in German, typical diminutives are always neuter. ${ }^{9}$ In SMG and some southern Greek dialects (e.g., Cretan, (14a)) the diminutive suffix - aki forms neuter words from masculine or feminine bases. The same behavior is attested with the diminutive suffixes of peripheral dialects, see for instance, -el' in Aivaliot, -opon in Pontic, and -okko in Cappadocian:

${ }^{9}$ For a detailed descriptive work on diminutives in German, Dutch and Polish, see Klimaszewska (1983). 
(14) (a) SMG / Cretan

$\begin{array}{ll}\text { kip-aki.neu } & <\text { kip.masc-os } \\ \text { little garden } & \text { garden } \\ \text { vris-aki.neu } & <\text { vrisi.fem- } \emptyset \\ \text { little fountain } & \text { fountain }\end{array}$

(b) Aivaliot

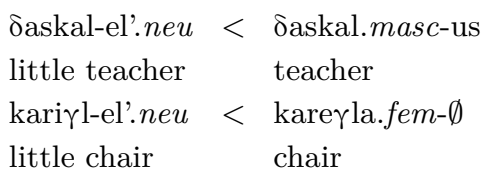

(c) Pontic

$\begin{array}{ll}\text { nif-opon.neu } & <\text { nif.fem-e } \\ \text { little bride } & \text { bride } \\ \text { paxtsaó-opon.neu } & <\text { paxtsa.masc-s } \\ \text { little garden } & \text { garden }\end{array}$

(d) Cappadocian (Dawkins 1916)

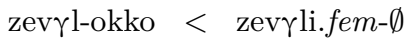

collar attached to the yoke

kor-okko < kork.masc-os

little yolk yolk

It should be noticed that while in SMG it is possible for a base to preserve its masculine gender after undergoing diminution, the masculine value is restricted in Pontic only to animate nouns denoting affinity, but is totally absent from the other dialectal varieties, where diminutive formations are predominantly neuter, and to a lesser extent feminine:

(15) (a) SMG

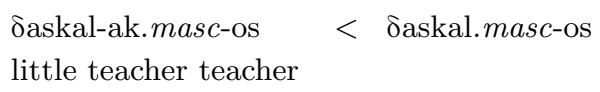

(b) Pontic

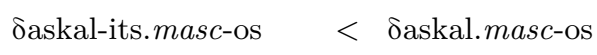

(c) Cappadocian

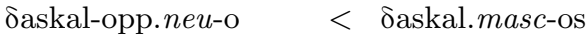

(d) Aivaliot

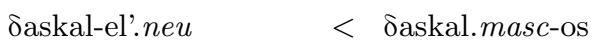

Interestingly, the exclusion of the masculine gender from the dialectal cases of diminutive formations and the predominance of the neuter value 
is in accordance with Daltas $(1985,72)$ and Grandi $(2002,33)$, in that the latter functions as a classificatory notion in diminution, and is considered the unmarked value of diminutive formations.

\subsection{Inflection class}

Further support to the claim that Greek diminutive suffixes constitute heads provides the fact that they determine the inflection class of the derived form, independently of the inflection class of the base, as the following examples illustrate:

(16) (a) SMG

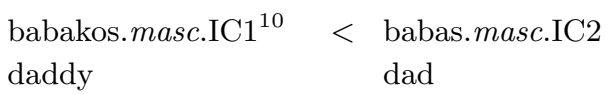

(b) Aivaliot

matsel'.neu.ICx < matsu.neu.ICy

small bundle bundle

(c) Pontic

xorafopon.neu. ICx $<$ xorafi(n).neu.ICz

small field field

Crucially, as the examples in (17) illustrate, the change in inflection class after diminution is particularly obvious in Grico, in spite of the fact that the dialect has undergone a heavy influence from Italian.

(17) Grico (Stomeo 1992)

$\begin{array}{lrl}\text { anemuddhi.neu.ICx } & <\text { anemo.masc.ICz } \\ \text { little wind } & \text { wind } \\ \text { andzeluddhi.neu.ICx } & <\text { andzelo.masc.ICz } \\ \text { little angel } & \text { angel } \\ \text { kokkaluddhi.neu.ICx } & <\text { kokkalo.neu.ICy } \\ \text { little bone } & \text { bone }\end{array}$

little bone bone

${ }^{10}$ According to Ralli (2000), there are eight nominal inflection classes in SMG. Since there is no particular analysis of the inflection classes in the dialects dealt with in this paper, we refer to them as ICx, ICy, and ICz where, $\mathrm{x}, \mathrm{y}$ and $\mathrm{z}$ are variables. 


\subsection{Inheritance of irregular morphology}

Significant evidence to the claim that diminutive suffixes are heads is also provided by certain irregularities of diminutive words which are absent from the base. For instance, SMG neuter formations do not have a genitive case, as opposed to the inflectional paradigms of their bases:

(18) SMG

$$
\begin{array}{lll} 
& \text { Base } & \text { Diminutive formation } \\
\text { Nom./Acc./Voc. } & \text { peôi } & \text { peó-aki } \\
\text { Gen. } & \text { peôj-u } & -
\end{array}
$$

It might be argued that this gap could be a general characteristic of diminutive formations in general, or a phenomenon that is triggered by pragmatic factors, as noted by Triantaphyllides (1941). However, this is not the case since words in -aki in the dialect of the island of Chios inflect for genitive (e.g., peo-aki-u 'child.gen'. Moreover, other SMG diminutive suffixes do not display the same gap. Consider, for instance, the diminu-

\begin{tabular}{|c|c|c|}
\hline $\begin{array}{l}\text { Nom./Acc./Voc. } \\
\text { Gen }\end{array}$ & $\begin{array}{l}\text { Base } \\
\text { porta 'door' } \\
\text { porta-s }\end{array}$ & $\begin{array}{l}\text { Diminutive formation } \\
\text { port-itsa 'little door' } \\
\text { port-itsa-s }\end{array}$ \\
\hline Nom & סaskal-os 'teacher' & Saskal-ak-os 'little teacher' \\
\hline Gen & Saskal-u & Saskal-ak-u \\
\hline Acc & Saskal-o & Saskal-ak-o \\
\hline Voc. & Saskal-e & Saskal-ak-e \\
\hline
\end{tabular}
tive words ending in the -itsa and -ak(os) suffixes:

(19) SMG

Thus, the absence of genitive case is a lexical, idiosyncratic irregularity of the SMG diminutive suffix -aki, which is transmitted to the diminutive formation through headedness and feature percolation.

The situation is similar in the diminution of certain peripheral dialects as well. In Aivaliot, for example, as shown in (20), diminutives in -el' miss the genitive case. However, the other Aivaliot diminutive suffixes, $-u \delta a$ and $-i$, do not behave in the same way. 
(20) Aivaliot

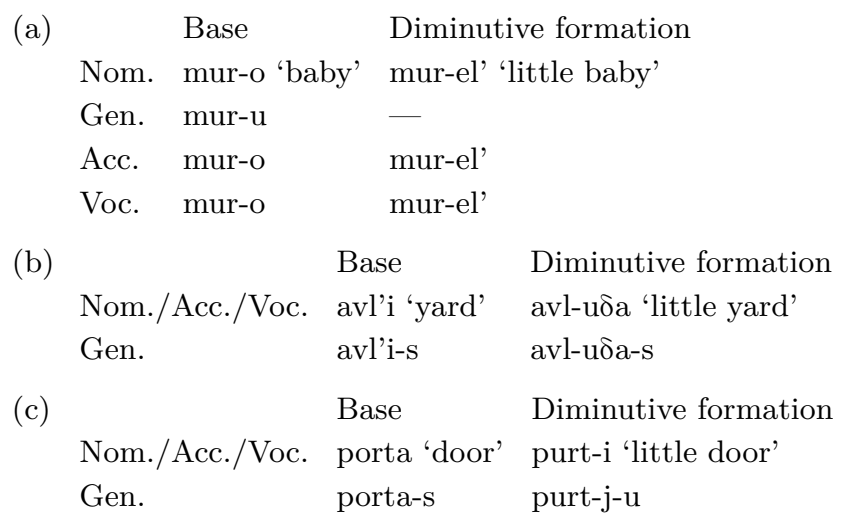

\section{Proposal}

We have seen that both SMG and dialectal diminutive suffixes are responsible for passing up a set of features to their formations. These features are of semantic, morphosyntactic (i.e., gender), and morphological (i.e., inflection class) nature. Diminutive suffixes may also be responsible for certain gaps of the inflectional paradigms of diminutive words. The inheritance of all these features by diminutive formations cannot be accounted for unless diminutive suffixes constitute heads. The following two points need be stressed:

(a) With the exception of some cases, where the meaning of diminutive formations becomes non-compositional (cf. (13)), diminutive suffixes do not usually cause a radical change to the meaning of the base. ${ }^{11}$ Assuming that there is a distinction between the notions of semantic and structural heads (cf. Zwicky 1985), we accept diminutive suffixes to fulfill the requirements for being the structural heads of their constructions, while, in most cases, the base preserves its right to be a semantic head.

(b) Diminutive suffixes behave differently from inflectional ones with respect to headedness: they may not change only the morphosyntactic features of the base (the categorial signature in Lieber's (1989) terms), but some semantic features as well, or add certain idiosyncratic properties. This behavior makes diminutive suffixes to act like heads.

${ }^{11}$ About the meaning of the Greek diminutive formations, see footnote 4 . 
As an illustration, the following schema represents the percolation of features from the constituent parts to the SMG diminutive word $\delta$ romaki 'little road' (< Sromos 'road'):

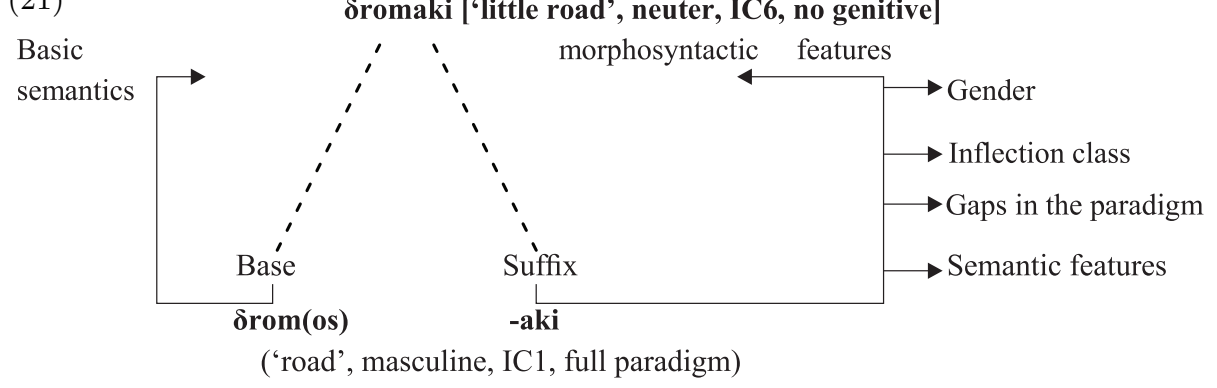

Crucially though, what merits further investigation is the cross-linguistic value of our claims. In other words, to what extent the derivational status and the headship properties of diminutive suffixes are language specific, or depend on the properties of the particular languages.

It is important to stress that even within the same linguistic group, we have attested considerable variety in the behavior of diminutive suffixes, in that there are Greek dialectal systems that strongly support our claims, and other systems that seem to adopt a weaker version of them. For instance, in SMG (official state dialect) there is a high alternation among diminutive suffixes that combine with the same base (7). This is a property which could be used as an argument against a clear derivational status. On the contrary, in Aivaliot, Cappadocian and Pontic the alternation is limited only in relation to feminine bases (i.e., bases accepting the suffixes -itsa or - $u d a$, depending on the case, see (9)), while in Grico there is no alternation at all (8). Let us repeat some examples for clarity:

(22) (a) SMG

melis-ula / melis-itsa / melis-aki / melis-uli < melisa little bee

bee

(b) Aivalot

vark-ula / vark-el' < varka

little boat boat

(c) Pontic

triץon-opon / triץon-itsa $<$ triץona

little turtledove turtledove 
(d) Cappadocian

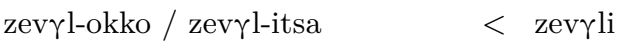

$$
\begin{aligned}
& \text { little collar attached to the yoke collar attached to the yoke }
\end{aligned}
$$

A plausible hypothesis would be to assume that within the same language there are dialects where diminutive suffixes look more like inflectional, and dialects where they behave more like derivational ones. However, this is not the case since within the same dialect diminutive suffixes do not behave uniformly with respect to their features. In particular, if Greek diminutive suffixes belong to inflection, we would expect them to show a considerable degree of consistency with respect to the following two features, which distinguish Greek inflectional affixes from derivational ones:

(a) Transparency to the grammatical category of the base, in that the same diminutive suffixes should attach to both adjectives and nouns.

(b) Sensibility to the gender of the base, because the form of Greek inflectional affixes is generally related to the gender value of the base (see Ralli 2002 for details).

As already seen, in Aivaliot the most productive diminutive suffix -el' is category neutral, since it attaches to both nominal and adjectival bases, without changing their category. In this respect, it behaves like inflection.

(23) Aivaliot
(a) aӨrup-el'.N.neu $<$ aӨrup-us.N.masc little man man
(b) purt-el'N.neu $<$ porta.N.fem little door door
(c) umurf-el'.A $\quad<$ omurf-u.A little pretty pretty

-el' does not belong to inflection though because its form is independent of the gender value of the base. In fact, a possible change of this gender value is the most typical characteristic of Greek derivational affixes.

(24) Aivaliot
(a) aөrup-el'.N.neu
$<$ aقrup-us.N.masc
little man
man 


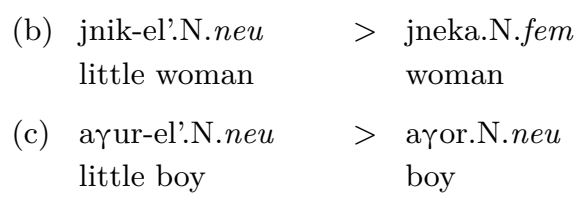

In addition, as far as categorial neutrality is concerned, the situation is exactly the opposite in certain other Greek dialects, for instance in SMG and Pontic, where nouns and adjectives have their own diminutive suffixes (see also (3) above):

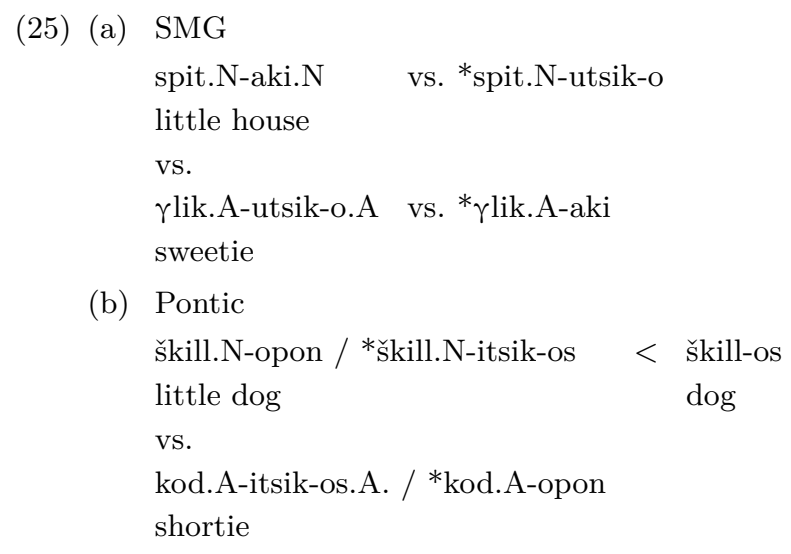

In an effort to propose a solution, we would like to invoke Scalise's (1988; 1994) idea about evaluative morphology being situated between inflection and derivation. However, instead of accepting a radical separation of three morphological subcomponents, which would include a radical separation of their affixal entities as well, we assume that the various processes and affixes are parts of a morphological continuum, in Bybee's (1985) sense, where pure derivation and pure inflection are situated at the two poles, and evaluative morphology between the two (see also Ralli 2005). The postulation of a morphological continuum containing wordformation processes and affixes in a scalar hierarchy has more generalizing power on a cross-linguistic level than the assumption of an autonomous subcomponent assigned to evaluative morphology. In this organization of morphology, and depending on the properties of the particular diminutive suffixes, we assume that although they are derivational, some of them are situated closer to inflection, while others are closer to pure derivation. This morphological continuum may accommodate not only the variation that is observed among diminutive suffixes within the same linguistic sys- 
tem and genetically related systems (i.e., dialects of the same language), but also variation across languages that are genetically unrelated. First, with respect to the same linguistic system, e.g., SMG, we could explain why some diminutive suffixes seem to have properties that are not typically derivational (see the -akos and -itsa cases that are category and gender transparent, see (3)), while other diminutive suffixes (e.g., the - aki suffix that changes the gender of the base) are clearly derivational. Second, in genetically related systems, e.g., Pontic and Cappadocian, we could interpret the fact that although both dialects share a lot of common features, Pontic has certain diminutive suffixes that are closer to SMG (see the masculine -itsis/-utsos suffixes as in (6)), the same suffixes being absent from Cappadocian. Moreover, we could also account for the inflection-like properties of diminutive suffixes in some languages, e.g., Fula as reported by Anderson (1992), or the clear derivational behavior of suffixes of other languages (see the Dutch cases described by Booij 2005).

Finally, it is important to stress the contribution of dialectal evidence to our claims. Several examples from Modern Greek dialects have shown that in spite of the fact that a dialect may be heavily influenced by another unrelated linguistic system (another language), the dialect still keeps the derivational features and the headedness status of the diminutive suffixes of its parent language, and sometimes reinforces them. Grico is a typical example illustrating this observation: although it has been in close contact with Italian, its diminutive suffixal system displays, among other things, the most characteristic derivational features of Greek, i.e., non-transparency to the gender and the category of the base.

\section{References}

Anderson, Stephen R. 1992. A-morphous morphology. Cambridge University Press, Cambridge.

Aronoff, Mark 1976. Word formation in generative grammar. MIT Press, Cambridge MA.

Barker, Mark 1964. Klamath grammar. University of California Press, Berkeley.

Bauer, Laurie 1983. English word-formation. Cambridge University Press, Cambridge.

Bauer, Laurie 1997. In search for universals. In: Studies in Language 21 :533-57.

Booij, Geert 1995. Inherent vs. contextual inflection and the Split Morphology Hypothesis. In: Geert Booij- Jaap van Marle (eds): Yearbook of morphology 1995, 1-16. Kluwer, Dordrecht. 
Booij, Geert 2005. The grammar of words: An introduction to linguistic morphology. Oxford University Press, Oxford.

Bybee, Joan 1985. Morphology. A study of the relation between meaning and form. John Benjamins, Amsterdam \& Philadelphia.

Daltas, Pericles 1985. Some patterns of variability in the use of diminutive and augmentative suffixes in Spoken Modern Greek Koine. In: Glossologia 4:63-88.

Dawkins, Richard 1916. Modern Greek in Asia Minor. Cambridge University Press, Cambridge.

Di Sciullo, Anna Maria-Edwin Williams 1987. On the definition of word. MIT Press, Cambridge MA.

Dressler, Wolfgang U. 1989. Prototypical differences between inflection and derivation. In: Zeitschrift für Phonetik, Sprachwissenschaft und Kommunikationsforschung $42: 3-10$.

Dressler, Wolfgang U. - Lavinia Merlini-Barbaresi 1992. Italian diminutives as nonprototypical word formation. In: Livia Tonelli-Wolfgang U. Dressler (eds): Natural morphology-perspectives for the nineties, 21-30. Unipress, Padova.

Dressler, Wolfgang U. - Lavinia Merlini-Barbaresi 1994. Morphopragmatics: Diminutives and intensifiers in Italian, German and other languages. Mouton de Guyter, Berlin \& New York.

Filieri, Giorgio 2001. Ivò Milò to Griko [I speak Grico]. University of Ioannina, Centre of Greek Language and Culture, Ioannina.

Grandi, Nicola 2002. Suffissi Valutativi. Francoangelli, Milano.

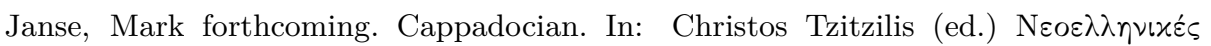

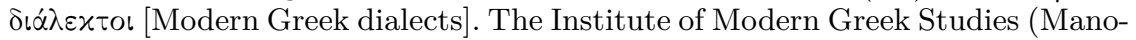
lis Triandaphyllidis Foundation), Thessaloniki.

Katramadou, Kouzinia 2001. The Greek diminutive. Doctoral dissertation, Rand Afrikaans University.

Klimaszewska, Zofia 1983. Diminutive und augmentative Ausdrucksmöglichkeiten des Niederländischen, Deutschen und Polnischen: Eine konfrontative Darstellung. Wydawnictwo Polskiej Akademii Nauk, Wrocław.

Koutita-Kaimaki, Mirto 1984. O Ipokorismos stin Pontiaki Dialekto [Diminution in Pontic]. Doctoral dissertation, University of Thessaloniki.

Kretschmer, Paul 1905. Der Heutige Lesbischen Dialekt. Alfred Holder, Wien.

Lieber, Rochelle 1989. On percolation. In: Geert Booij- Jaap van Marle (eds): Yearbook of morphology 2, 95-138. Foris, Dordrecht.

Oikonomidis, Dimosthenis 1958. Grammatiki tis Ellinikis Dialektou tou Pontou [Pontic grammar]. Academy of Athens, Athens.

Ralli, Angela 1988. Eléments de la morphologie du grec moderne. Doctoral dissertation, University of Montreal.

Ralli, Angela 2000. A feature-based analysis of Greek nominal inflection. In: Glossolojia $11-12: 201-28$.

Ralli, Angela 2002. The role of morphology in gender determination: Evidence from Modern Greek. In: Linguistics $40: 519-551$. 
Ralli, Angela 2005. Morfologia [Morphology]. Patakis, Athens.

Ralli, Angela forthcoming. The dialect of Kydonies (Aivaliot) and Moschonisia.

Rohlfs, Gerhard 1977. Grammatica Storica dei Dialetti Italogreci. C. H. Becksche, München.

Scalise, Sergio 1988. The notion of 'head' in morphology. In: Geert Booij- Jaap van Marle (eds): Yearbook of morphology 1, 229-45. Foris, Dordrecht.

Scalise, Sergio 1994. Morfologia. Il Mulino, Bologna.

Selkirk, Elizabeth O. 1982. The syntax of words (Linguistic Inquiry Monograph 7). MIT Press, Cambridge MA.

Stomeo, Paolo 1992. Vocabolario Greco-Salentino. Centro di Studi Salentini, Lecce.

Stump, Gregory T. 1993. How peculiar is Evaluative Morphology? In: Journal of Linguistics $29: 1-36$.

Triantaphyllides, Manolis 1941. Neoelliniki Grammatiki [Modern Greek grammar]. Manolis Triantaphyllides Institute, Thessaloniki.

Williams, Edwin 1981. On the notions 'lexically related' and 'head of a word'. In: Linguistic Inquiry $12: 245-74$.

Zwicky, Arnold 1985. Heads. In: Journal of Linguistics 21:1-29. 